\title{
BMJ Open COVID-19 prevention practices in urban setting during early introduction of the disease: results from community survey in SNNP Region, Ethiopia
}

\author{
Misganu Endriyas (D , , Aknaw Kawza, ${ }^{2}$ Abraham Alano, ${ }^{3}$ Mamush Hussen, ${ }^{4}$ \\ Endashaw Shibru ${ }^{4}$
}

To cite: Endriyas M, Kawza A, Alano A, et al. COVID-19 prevention practices in urban setting during early introduction of the disease: results from community survey in SNNP Region, Ethiopia. BMJ Open 2021;11:e047373. doi:10.1136/ bmjopen-2020-047373

- Prepublication history and additional supplemental material for this paper are available online. To view these files, please visit the journal online (http://dx.doi.org/10.1136/ bmjopen-2020-047373).

Received 05 December 2020 Accepted 28 April 2021

\section{Check for updates}

(c) Author(s) (or their employer(s)) 2021. Re-use permitted under CC BY-NC. No commercial re-use. See rights and permissions. Published by BMJ.

${ }^{1}$ Health Research and Technology Transfer, Southern Nations, Nationalities and People's Region Health Bureau, Hawassa, Ethiopia

${ }^{2}$ Head Office, Southern Nations, Nationalities and People's Region Health Bureau, Hawassa, Ethiopia

${ }^{3}$ SNNPR President Office, SNNPR Policy Study and Research Institute, Hawassa, Ethiopia

${ }^{4}$ Public Health Institute, Southern Nations, Nationalities and People's Region Health Bureau, Hawassa, Ethiopia

Correspondence to

Mr Misganu Endriyas;

misganuendrias@yahoo.com

\section{ABSTRACT}

Objective To assess community practices related to COVID-19 prevention and its associated factors during the early introduction of the disease to the study area. Setting and participants A community-based crosssectional study was conducted in Southern Nations, Nationalities and People's Region, Ethiopia. Ten zonal towns with high population density and mobility and 1239 participants were included in the study.

Outcome measure A semistructured questionnaire was uploaded to SurveyCT0 data collection system with security patterns. Mask usage was assessed by observation, while social distancing and handwashing were assessed by interview. Data were collected by health professionals who have Bachelor of Science degree and above and analysed using SPSS V.25. Descriptive statistics and binary logistic regression were performed.

Results From 1239 individuals, about half, 657 (53\%), of respondents were women and about two-thirds, 795 (64.2\%), were married. Nearly 9 out of $10(90.3 \%)$ and about 8 out of $10(82.0 \%)$ respondents reported that they frequently wash hands with soap and/or use sanitiser and keep social distancing as means to prevent COVID-19, respectively. Less than three-fifths $(57.8 \%)$ of respondents wore masks during the interview. In summary, about half $(48.9 \%)$ of respondents were practising the three recommended methods (social distancing, handwashing and wearing masks). Sex, educational status, family size and overall knowledge about COVID-19 were associated with practising COVID-19 prevention measures.

Conclusion COVID-19 prevention practice was low as only about half of participants were practising social distancing, handwashing and wearing masks. Although awareness creation has been implemented through different forms of media, it should be strengthened in different local languages. Concerned government bodies should strictly follow using masks in public gatherings.

\section{INTRODUCTION}

COVID-19 is a highly infectious viral disease, and its main clinical symptoms include fever, dry cough, fatigue, myalgia and dyspnoea. ${ }^{12}$ COVID-19 as a pandemic continues, causing huge social and economic impact and stress on the healthcare system of all countries in
Strengths and limitations of this study

- The current study was first to cover multicentres (10 zonal towns) and report regional-level COVID-19 prevention practices at community level.

- The study could reach to adequate sample in the community during the early introduction of the disease to the study setting while there was great fear.

- Even though this study covered majority of towns in the region, this study was limited in addressing smaller towns and rural areas that account for the majority of the regional population.

- In addition, though the tool was checked for content and face validity, construct validity was not performed using statistical tests.

the world, ${ }^{34}$ though many efforts have been carried out to contain the virus since the declaration of the disease as a pandemic. ${ }^{5}$

Prevention of COVID-19 in an urban setting of developing countries is challenging because of dense population, small informal dwellings, lack of access to clean water, multigenerational households with shared sanitation facilities, high level of social mixing and transient residents. ${ }^{67}$ In addition, the presence of non-specific symptoms of endemic illnesses such as malaria and influenza in developing countries makes it difficult to differentiate those from COVID-19 symptoms. ${ }^{6}$

In Ethiopia, the first case of COVID-19 was registered in March 2020; and in the study region, it was registered in early May 2020. Since then, the Ministry of Health and regional health bureaus, in collaboration with different stakeholders, have been doing different activities to prevent and control the spread of the disease, but there was information gap on communities regarding COVID-19 prevention practices. To assist these responses, this study assessed practices 
related to COVID-19 prevention activities and its associated factors in selected zonal towns in Southern Nations, Nationalities and People's Region (SNNPR), Ethiopia.

\section{METHODS}

A community-based cross-sectional study was carried out from 18 May to 10 June 2020 in selected towns of SNNPR. SNNPR was the third largest region representing nearly $20 \%$ of the population of the country. The region had more than 56 ethnic groups and languages, making it the most diverse region in the country. The region was administratively subdivided into 18 zones, 1 city administration and 7 special woredas. Woreda is an administrative structure equivalent to a district with approximately 100000 population. According to the census of 2007, in 2019/2020, the total population of the region was projected to be about 20.5 million. ${ }^{8}$

Sample size was estimated using a single population proportion formula at $95 \%$ confidence level, assuming proportion of population with good practice to be $50 \%$ and considering $5 \%$ margin of error, design effect of three and $10 \%$ non-response rate. The final sample size was 1268 . The calculated sample size was allocated to 10 zonal towns based on the size of the population. Ten towns were purposely selected considering the potential risk of COVID-19, crowdedness and high mobility.

At the time of data collection, the country declared a state of emergency that was not strict where some people were moving in towns while the majority stayed at home. To include both populations staying at home and out of home, one-third of estimated sample size was allocated to out-of-home population in towns and the rest two-thirds were allocated to population staying at home.

In the study setting, towns are structured to the smallest administrative unit, kebeles. Kebeles in the towns were listed and two sample kebeles were selected randomly from each town. To select individual respondents, data collectors went to the centre of selected kebeles and spin pen to select the direction to start at the first house. The next household was selected from the next adjacent block in parallel position and continued until the sample size was fulfilled. Concerning the out-of-home population, every other person that data collectors met while moving to the next block was selected and interviewed, and this continued until the sample size was fulfilled. Residing in the selected kebeles for at least 6 months and age above 18 years were considered as eligibility criteria.

The questionnaire (online supplemental file 1) was prepared by reviewing relevant literature..$^{79}$ The tool consisted of sociodemographic characteristics, exposure to COVID-19, messages and knowledge, attitude and practice about COVID-19 and its prevention. Almost all questions had 'others' option and space to type other responses. The prepared tool was then shared with members of Emergency Operation Center (EOC) of COVID-19 response at regional level and Hawassa University Scientific Advisory Committee to address face and content validity of the questionnaire and to understand that questions can capture required data. EOC consists of experts from regional health bureaus, local and international partners working on COVID-19 response, Hawassa Health Science College and Hawassa University. The questionnaire was initially prepared in English and then translated to Amharic parallelly by investigators that comprise different public health experts, and complemented for better version. The data collection tool was then uploaded to SurveyCTO data collection system with security patterns. Training was given to data collectors to have common understanding on data collection tools and process. Tool pretest was done in urban settings not included in actual study to familiarise data collectors and to test if there were any challenges during interview, and modifications were made based on field feedback. Nine data collectors who had Bachelor of Science degree and above and experience in data collection conducted face-to-face interviews, keeping COVID-19 prevention measures like social distancing and wearing masks. Field supervision and online monitoring were done daily to maintain data quality.

The Excel file downloaded from SurveyCTO server was exported to SPSS V.25 for data management. Those respondents with no information about COVID-19 were excluded from the main analysis. Descriptive statistics (like frequency, percentages, mean and SD) were used to describe study participants and variables. Potential predictors of practice were determined using binary logistic regression. Independent variables with $\mathrm{p}$ value of less than 0.20 during bivariate binary logistic regression analysis were included in multivariate binary logistic regression model. Finally, variables with $\mathrm{p}$ value of less than 0.05 during multivariate binary logistic regression were considered to have statistically significant association and were reported with adjusted OR (AOR) and 95\% CI.

\section{Patient and public involvement}

Even though respondents were not involved in the design, we disseminated the findings to stakeholders working on COVID-19 prevention and control, and findings were also disseminated through local media.

\section{RESULTS}

Overall, 1239 respondents were included in the study, with a response rate of $97.7 \%$. The reason for nonresponse, mainly, was the fear of COVID-19 transmission during the interview.

\section{Sociodemographic characteristics of respondents}

About half, 657 (53\%), of respondents were women and about two-thirds, 795 (64.2\%), were married (table 1).

\section{Knowledge about and attitude towards COVID-19}

Seven knowledge questions about signs and symptoms, diagnosis of the disease, what to do if there is a suspect, drug to cure the disease, transmission mechanisms, 


\begin{tabular}{|c|c|c|c|}
\hline Variables & Category & Frequency & Per cent \\
\hline \multirow[t]{2}{*}{ Sex } & Male & 582 & 47.0 \\
\hline & Female & 657 & 53.0 \\
\hline \multirow[t]{7}{*}{ Age } & $\leq 25$ & 304 & 24.5 \\
\hline & $26-30$ & 214 & 17.3 \\
\hline & $31-35$ & 145 & 11.7 \\
\hline & $36-40$ & 148 & 11.9 \\
\hline & $41-45$ & 74 & 6.0 \\
\hline & $46+$ & 213 & 17.2 \\
\hline & I don't know & 141 & 11.4 \\
\hline \multirow[t]{5}{*}{ Marital status } & Single & 370 & 29.9 \\
\hline & Married & 795 & 64.2 \\
\hline & Divorced & 36 & 2.9 \\
\hline & Widowed & 31 & 2.5 \\
\hline & Living separately & 7 & 0.6 \\
\hline \multirow[t]{4}{*}{$\begin{array}{l}\text { Educational } \\
\text { status }\end{array}$} & $\begin{array}{l}\text { No formal } \\
\text { education }\end{array}$ & 126 & 10.2 \\
\hline & Primary (1-8) & 249 & 20.1 \\
\hline & Secondary (9-12) & 375 & 30.3 \\
\hline & $\begin{array}{l}\text { Certificate and } \\
\text { above }\end{array}$ & 489 & 39.5 \\
\hline \multirow[t]{9}{*}{ Occupation } & Student & 172 & 13.9 \\
\hline & Farmer & 29 & 2.3 \\
\hline & Merchant & 315 & 25.4 \\
\hline & Employee & 340 & 27.4 \\
\hline & Housewife & 208 & 16.8 \\
\hline & Daily labourer & 42 & 3.4 \\
\hline & Pensioner & 30 & 2.4 \\
\hline & Private & 52 & 4.2 \\
\hline & Other & 51 & 4.1 \\
\hline \multirow[t]{2}{*}{ Family size } & $\leq 5$ & 858 & 69.2 \\
\hline & $\geq 6$ & 381 & 30.8 \\
\hline \multirow[t]{4}{*}{ Religion } & Orthodox & 475 & 38.3 \\
\hline & Protestant & 594 & 47.9 \\
\hline & Muslim & 137 & 11.1 \\
\hline & Others & 33 & 2.7 \\
\hline
\end{tabular}

prevention methods and most at-risk groups were asked to determine level of knowledge. In summary, the mean score of knowledge was $52.3 \%(\mathrm{SD}=18.9)$. Knowledge score was categorised using quartiles where the first quartile was labelled as poor and fourth quartile was labelled good, while second and third quartiles were labelled as medium.

Eleven different attitude statements about the seriousness of disease, being at risk, possibility of prevention and benefits of staying at health facilities were given to respondents and their agreement to statements was measured using a 5-point Likert scale, from strongly disagree to

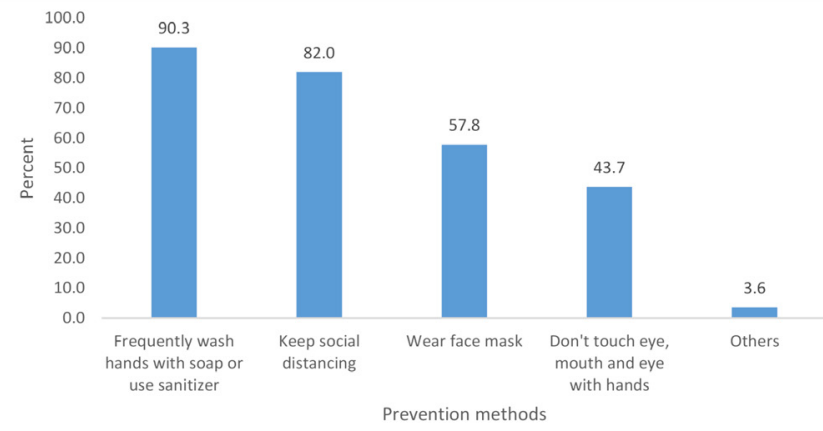

Figure 1 Respondents' measures to prevent COVID-19, SNNPR, 2020. Others: cover coughs and sneezes with elbow, wear gloves, take hot drinks, keep outdoor clothes out, stopped eating raw food, pray, do sport, frequently check temperature and take vitamin C. SNNPR, Southern Nations, Nationalities and People's Region.

strongly agree. The overall sum of attitude responses showed that the mean score was $80.8 \%(\mathrm{SD}=6.48)$. The overall score was categorised to quartiles where the first quartile was considered as negative attitude, second and third quartiles were considered as neutral, while fourth quartile was labelled as positive attitude.

\section{Practice regarding COVID-19 prevention}

Nearly 9 from $10(90.3 \%)$ and about 8 from $10(82.0 \%)$ respondents reported that they frequently wash hands with soap and/or use sanitiser and keep social distancing as means to prevent COVID-19, respectively. Less than three-fifths $(57.8 \%)$ of respondents wore masks during the interview (figure 1).

\section{Using masks}

About two-fifths, 521 (42.2\%), were not using any kind of masks during the interview. From those who wore masks, $212(29.7 \%)$ were using medical masks (any kind) while others were using non-medical masks. Unavailability of masks was the major reason $(58.6 \%)$ for not wearing masks and other reasons were presented in figure 2.

In summary, 605 (48.9\%) were practising social distancing, cleaning hands and wearing masks.

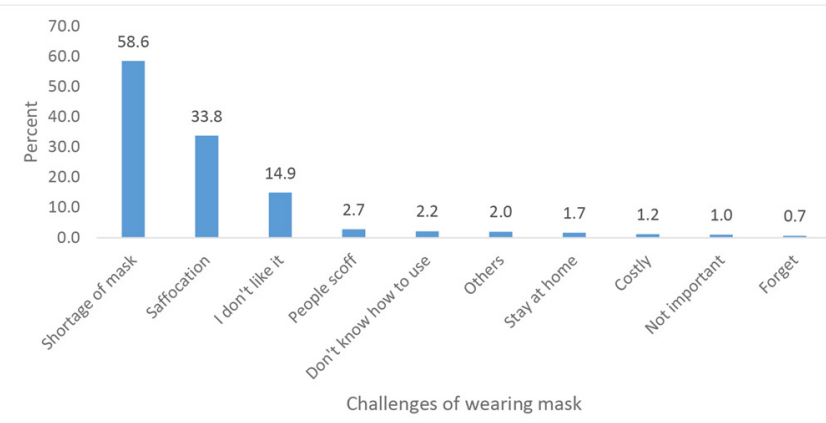

Figure 2 Reasons for not wearing masks, SNNPR, 2020. Others: allergy, don't know where to get, hot environment, medical problem, negligence, not sure of quality, think it (itself) brings the disease. SNNPR, Southern Nations, Nationalities and People's Region. 


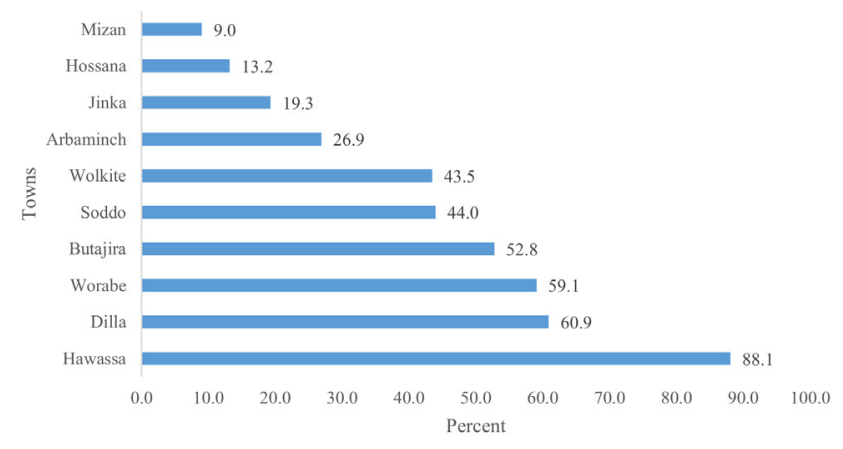

Figure 3 COVID-19 prevention practice among towns, SNNPR, 2020. SNNPR, Southern Nations, Nationalities and People's Region.

The practice was highest in Hawassa $(88.1 \%)$ and lowest in Mizan (9.0\%) (figure 3).

\section{Factors associated with COVID-19 prevention practice}

After running multivariate binary logistic regression, sex, educational status, family size and overall knowledge about COVID-19 were associated with practising COVID-19 prevention measures (table 2).

Women were $44 \%$ more likely to practise COVID-19 prevention measures as compared with male respondents (AOR at 95\% CI: 1.44 (1.08 to 1.92)). Those who attended primary and secondary education, and had certificate and above education were $89 \%, 74 \%$ and $89 \%$ more likely to practise COVID-19 prevention measures, respectively, as compared with those who never attended education.

Respondents from larger ( $\geq 6$ members) household were $39 \%$ more likely to practise COVID-19 prevention measures as compared with those who had fewer number of family members ( $\leq 5$ members) (AOR at $95 \%$ CI: 1.39 (1.04 to 1.84)).

Respondents who have medium-level and high-level knowledge scores were 2.04 and 2.47 times more likely to practise COVID-19 prevention measures as compared with respondents with poor knowledge scores (AOR at $95 \%$ CI: 2.04 (1.51 to 2.75) and 2.47 (1.80 to 3.40), respectively).

\section{DISCUSSION}

This study was done with the objective of assessing practices related to COVID-19 prevention methods and its associated factors, and the major finding was that only about half of respondents (48.9\%) were practising social distancing, cleaning hands and wearing masks. Sex, educational status, family size and overall knowledge about COVID-19 were associated with practising COVID-19 prevention measures.

Nearly 9 from $10(90.3 \%)$ and about 8 from $10(82.0 \%)$ respondents reported that they frequently wash hands with soap and/or use sanitiser and keep social distancing as means to prevent COVID-19, respectively. Less than three-fifths $(57.8 \%)$ of respondents wore masks during the interview; and in summary, only about half (48.9\%) of respondents were practising the three recommended methods (social distancing, cleaning hands and wearing masks). This result was low as compared with studies done in China ${ }^{10}$ that showed practise of more than $95 \%$ and Saudi Arabia ${ }^{9}$ that showed practise of $75 \%$ or more. This less practise as compared with other studies may be due to less attention given by the community due to smaller (less than hundred) cases in the region.

Respondents who attended primary and secondary education, and had certificate and above education were $89 \%, 74 \%$ and $89 \%$ more likely to practise COVID-19 prevention measures, respectively, as compared with those who never attended education. In addition, respondents who have medium-level and high-level knowledge scores were 2.04 and 2.47 times more likely to practise COVID-19 prevention measures as compared with respondents with poor knowledge scores (AOR at 95\% CI: 2.04 (1.51 to 2.75 ) and 2.47 (1.80 to 3.40 ), respectively). The level of education was also reported as a significant factor in the study conducted in Sidama and Tigrai regions of Ethiopia. ${ }^{11}{ }^{12}$ Moreover, studies done in South West Ethiopia, ${ }^{13}$ Tigrai $^{12}$ and Palestine ${ }^{14}$ added that level of knowledge is a significant factor of COVID-19 prevention. This indicated that level of awareness is important to prevent the disease.

Women were $44 \%$ more likely to practise COVID-19 prevention measures as compared with male respondents (AOR at 95\% CI: 1.44 (1.08 to 1.92)). Moreover, respondents from larger families ( $\geq 6$ members) were $39 \%$ more likely to practise COVID-19 prevention measures as compared with those who had fewer number of family members ( $\leq 5$ members) (AOR at 95\% CI: 1.39 (1.04 to 1.84)). A similar finding was reported by a study done in South West Ethiopia. ${ }^{13}$ This may be due to familial responsibilities to prevent the disease and opportunities to discuss the disease.

Even though this study was conducted early after the introduction of the disease to the region, awareness creation has been in place after early detection of the disease in China and the declaration of the disease as a pandemic. Response activities have been led in an organised way by the Ministry of Health and regional health bureaus since the introduction of the disease to the country. As part of their response, a state of emergency was declared and wearing masks was a must in some cases like in public transport and banks. Although there were misconceptions about using masks, the major reason for not using masks $(58.6 \%)$ was its unavailability, which lowered mask usage and overall practice among participants. In addition to overall low practice, there was huge variation of practice ranging from as low as $9 \%$ to $88.1 \%$. Improving access to masks and strengthening awareness creation on masks are crucial.

Because of the urgency of information needed during the early introduction of the pandemic to the study area, the tool used was limited as we did not validate it using statistical tests. Even though this study covered the 
Table 2 Binary and multivariate binary logistic regression

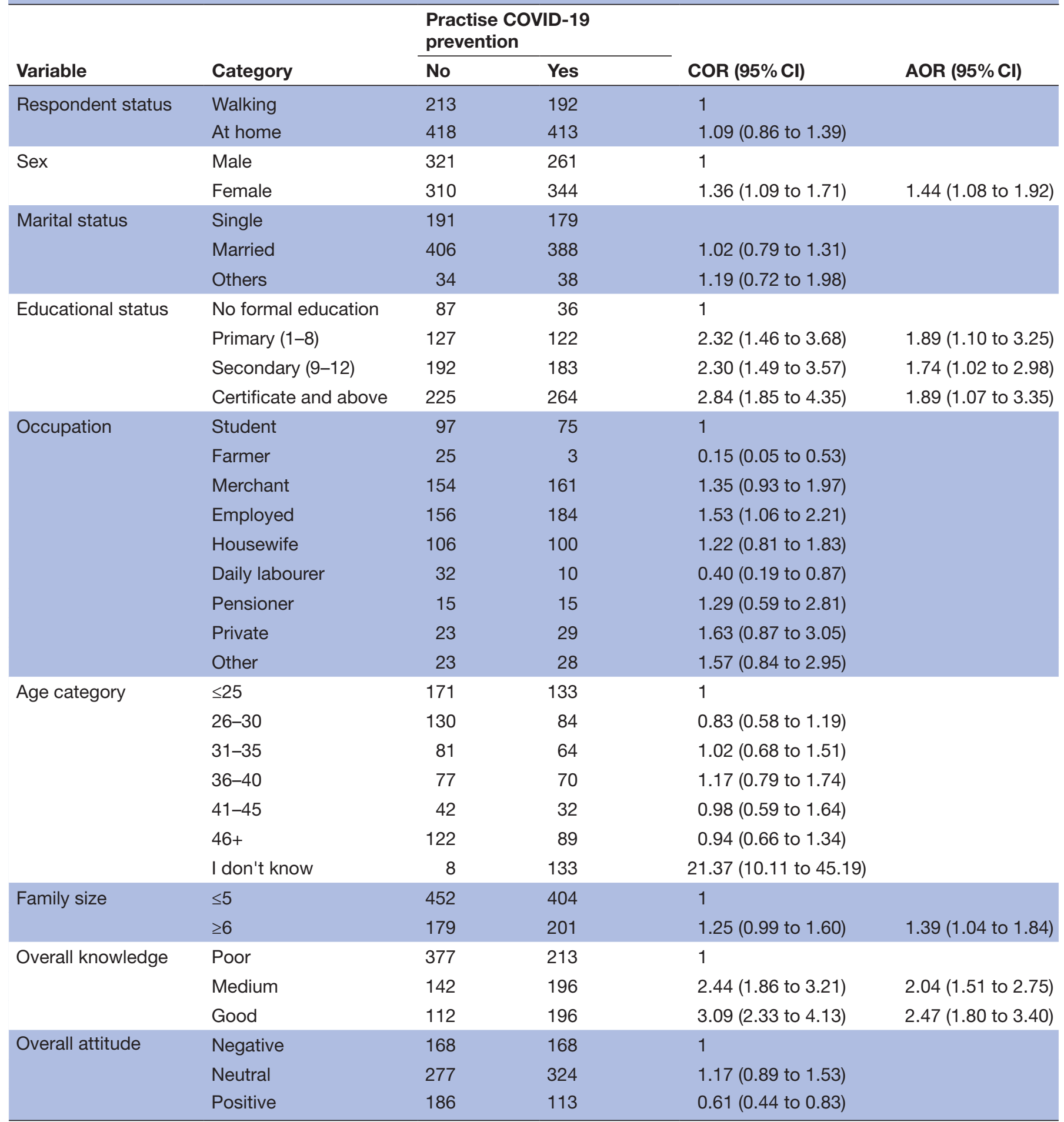

AOR, adjusted OR; COR, crude OR.

majority of towns in the region, this study was limited in addressing smaller towns and rural areas that account for the majority of the regional population. In addition, though we included respondents staying at home and those moving in towns, the sample size allocation may not exactly represent respective population segment. Moreover, some of the reported practices like social distancing might have been knowledge and may not be actual practice of respondents due to social desirability bias.

\section{CONCLUSION}

COVID-19 prevention practice was low as only about half of participants were practising social distancing, cleaning 
hands and wearing masks. Sex, educational status, family size and overall knowledge about COVID-19 were associated with practising COVID-19 prevention measures. Although awareness creation has been implemented through different forms of media, it should be strengthened in different local languages. Concerned government bodies should strictly follow using masks in public gatherings.

Acknowledgements We would like to thank Dobility for letting us avail of free data collection system for the COVID-19 survey as part of its response to tackle the pandemic. Special thanks to Audra E Blanchfield, SurveyCT0 team member in Dobility, for her support by converting community subscription server to 'COVID-19 dedicated server' in the middle of data collection.

Contributors All authors contributed to conceptualisation, design and data collection. ME developed SurveyCTO form and followed daily submitted data, managed data, and wrote the report and manuscript. AK, MH and ES facilitated financial support and managed the overall survey. AA reviewed the manuscript. All authors read and approved the final version.

Funding This study was supported by the SNNPR Health Bureau and Public Health Institute (award number not available). Manuscript writing was not supported financially.

Disclaimer The funder had no role in study design, data collection and analysis, decision to publish or preparation of the manuscript.

Competing interests None declared.

Patient consent for publication Not required.

Ethics approval Ethical clearance was obtained from the ethical review committee of the regional health bureau (reference number: $\left.£^{\prime} 6-19 / 6193\right)$. The study participants were informed about the purpose of the study and informed verbal consent was taken. Verbal consent was preferred and approved because of its popularity in the study setting and to minimise contamination during the pandemic. All collected data are kept confidential.

Provenance and peer review Not commissioned; externally peer reviewed.

Data availability statement Data are available upon reasonable request. All relevant data are within the manuscript. The datasets analysed during the current study are available from the corresponding author on reasonable request.

Supplemental material This content has been supplied by the author(s). It has not been vetted by BMJ Publishing Group Limited (BMJ) and may not have been peer-reviewed. Any opinions or recommendations discussed are solely those of the author(s) and are not endorsed by BMJ. BMJ disclaims all liability and responsibility arising from any reliance placed on the content. Where the content includes any translated material, BMJ does not warrant the accuracy and reliability of the translations (including but not limited to local regulations, clinical guidelines, terminology, drug names and drug dosages), and is not responsible for any error and/or omissions arising from translation and adaptation or otherwise.

Open access This is an open access article distributed in accordance with the Creative Commons Attribution Non Commercial (CC BY-NC 4.0) license, which permits others to distribute, remix, adapt, build upon this work non-commercially, and license their derivative works on different terms, provided the original work is properly cited, appropriate credit is given, any changes made indicated, and the use is non-commercial. See: http://creativecommons.org/licenses/by-nc/4.0/.

ORCID iD

Misganu Endriyas http://orcid.org/0000-0002-0026-9611

\section{REFERENCES}

1 World Health Organization. Investigation of cases of human infection with Middle East respiratory syndrome coronavirus (MERS-CoV): interim guidance. Geneva, Switzerland World Health Organization; 2018.

2 The Novel Coronavirus Pneumonia Emergency Response Epidemiology Team. The epidemiological characteristics of an outbreak of 2019 novel coronavirus diseases (COVID-19) in China. Chin J Epidemiol 2020;41:145-51.

3 Federal ministry of health [Ethiopia]. National comprehensive COVID19 management Handbook. Addis Ababa Federal ministry of health [Ethiopia]; 2020.

4 World Health Organization. Severe acute respiratory infections treatment centre practical manual to set up and manage a SARI treatment centre and a SARI screening facility in health care facilities. Geneva World Health Organization; 2020.

5 Alzoubi H, Alnawaiseh N, Al-Mnayyis Asma'a, et al. COVID-19 - Knowledge, Attitude and Practice among Medical and NonMedical University Students in Jordan. J. Pure Appl. Microbiol. 2020:14:17-24.

6 World Health Organization. Mental health and psychosocial considerations during the COVID-19 outbreak. Geneva World Health Organization; 2020.

7 Abuya T, Austrian K, Isaac A. COVID-19-related knowledge, attitudes, and practices in urban slums in Nairobi, Kenya. Population Council 2020.

8 SNNPR Regional Health Bureau. Annual plan of 2019/2020; 2020.

9 ALdowyan NM, Ahmed AS, El-Gharabawy RM. Knowledge, attitude and practice (KAP) study about middle East respiratory syndrome coronavirus (MERS-CoV) among population in Saudi Arabia. Int Arch Med 2020;10.

10 Zhong B-L, Luo W, Li H-M, et al. Knowledge, attitudes, and practices towards COVID-19 among Chinese residents during the rapid rise period of the COVID-19 outbreak: a quick online cross-sectional survey. Int J Biol Sci 2020;16:1745-52.

11 Yoseph A, Tamiso A, Ejeso A. Knowledge, attitudes, and practices related to COVID-19 pandemic among adult population in Sidama regional state, southern Ethiopia: a community based cross-sectional study. PLoS One 2021;16:e0246283.

12 Haftom M, Petrucka P, Gemechu K, et al. Knowledge, Attitudes, and Practices Towards COVID-19 Pandemic Among Quarantined Adults in Tigrai Region, Ethiopia]]\&gt. Infect Drug Resist 2020;13:3727-37.

13 Wondimu W, Ejigu A, Ayenew M, et al. Factors associated with coronavirus disease 2019 prevention practices in three zones of Southwest Ethiopia: community-based cross-sectional study. Int J Gen Med 2020;13:1603-11.

14 Qutob N, Awartani F. Knowledge, attitudes and practices (KAP) towards COVID-19 among Palestinians during the COVID-19 outbreak: a cross-sectional survey. PLoS One 2021;16:e0244925. 